1374 MYOINOSITOL SUPPLEMENTATION IN RESPIRATORY CISTRESS SYNDROME (RDS). Mikko Hallman, Anna-Li isa Jyrvenpyad, Pat Bromberger. Childrens' Hospital, Univ. Helsinki Finland; Dept. Pediatrics, Univ. California, San Diego, CA. Myoinositol (INO) may potentiate hormone-induced lung maturation \& increase surfactant in lung damage (Ped Res 17, 378 A, -83; Life Sci $31,175,-82$ ). Serum INO is high in RDS at birth. INO decreases after birth, in part because the diet may contain only little INO. In the present randomized double-blind trial involving 22 RDS cases (BW $<2000 \mathrm{~g}$ ), we studied the effect of INO on ing 22 RDS cases serum INO and on lung phospholipids. Either INO or glucose (GLU)
(dose: $1 \mathrm{ml}$ isotonic sugar/kg q $6 \mathrm{~h}$ ) was given orally for 7 days, beginning day two. The amount of INO was similar to INO present in $200 \mathrm{ml} / \mathrm{kg}$ of preterm breast milk. There was no differences in BW $(1273 \pm 57 \mathrm{~g}), \mathrm{GA}(29.3 \pm 0.4 \mathrm{wks})$, or severity of RDS during the first $48 \mathrm{~h}$, as compared between the INO and the GLU groups. Serum INO (NM) increased in INO group, and was different from GLU group: \begin{tabular}{cccccc} 
Age (days) & 1 & 3 & 7 & $\frac{1 \text { vs } 3}{\text { Ivs } 7}$ \\
\hline INO group & $734 \pm 137$ & $1047 \pm 149$ & $1187 \pm 177$ & $<0.0001$ & $<0.005$
\end{tabular} $\begin{array}{lrrrrr}\text { INO group } & 734 \pm 137 & 1047 \pm 149 & 1187 \pm 177 & <0.0001 & <0.005 \\ \text { GLU group } & 848 \pm 114 & 693 \pm 171 & 674 \pm 203 & <0.1 & <0.1\end{array}$ There were no differences in disaturated lecithin/sphingomyelin $(\mathrm{L} / \mathrm{S}$ ) from tracheal aspirates on day one (INQ: $1.9 \pm 0.4$; control $1.9 \pm 0.4)$. INO supplementation tended to increase $L / S$ (days $5-8$ : INO: $9.0 \pm 1.7$; GLU: $5.4 \pm 1.1, \mathrm{p}<0.05$ ). INO group (GLU) had follow ing complications: bronchopulmonary dysplasia $0 / 11(3 / 11)$; patent ductus arteriosus (indomethacin or surgery) 2(6); necrotizing enterocolitis 0 (1); intraventricular hemorrhage (>grade 1) 2(2). Present results justify further evaluation of the hypothesis that Present results justify further evaluation of the hypothes

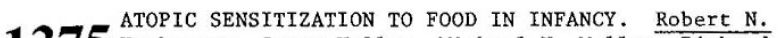
Hamburger, Susan Heller, Michae1 H. Mellon, Richard D. O'Connor and Robert S. Zeiger. UCSD, Department of Pediatrics, La Jolla, CA and Kaiser-Permanente, Allergy Department, San Diego, CA.

There is no definitive way to distinguish a true atopic IgE mediated sign or symptom due to a food from an intolerance reaction due to irritation, enzyme deficiency or other idiosyncratic cause. The presence of IgE specific antibody against a food as demonstrated by an immediate weal and flare skin test reaction or a positive RAST is presumptive evidence of a cause and effect relationship. The younger the patient the more and effect relationship. The younger the patient the more ally related to the 1llness. Never-the-less, in almost 100 infants at four months of age five were observed to have both a positive skin test and a positive RAST to a food, with only two having any detectable allergic illness. This observation in a prospective study of the value of a prophylaxis regimen in the prevention or amelioration of atopic allergic disease in infancy, underlines the problem of the ascertainment of allergy.

Under ordinary circumstances an individual with complaints, signs and symptoms of allergic disease consults the physician to help find the cause of the illness. In our double blind prospective study of the value of a prophylaxis regimen in the infants from highly atopic families, evidence of sensitization to food usually precedes the clinical appearance of signs and symptoms of illness. Thus the concordance of disease with positive tests is much lower than is the case in clinical practise.

\section{$\dagger 1376$} EFFECTS OF SEVERE HYPOXIA ON DILATOR PROSTAGLANDIN SYNTHESIS. John Lieske, Cathy Hammerman and Elene Department of Pediatrics, Chicago, IL.

The effects of severe hypoxia on dilator prostaglandin (PG) synthesis were studied in a neonatal rat model. Immediately after birth successively delivered rat pups were paired and randomly assigned to either a hypoxic $\left(3 \% 0_{2}\right)$ environment or room air. The pups in the hypoxic environment were visibly cyanotic by the end of the 1 hour study period. At this time the pairs were sacrificed concurrently and blood was collected for PG radioimmunoassay. Samples were pooled within a litter such that each litter would yield one pooled sample of "hypoxic" blood and one pooled sample of "normoxic" blood. Samples from 7 litters were assayed for PGE and 6-keto PGF. Both PG's decreased under severe hypoxia: mean PGE2 levels were decreased by about $80 \%$, while mean poxia: mean $\mathrm{PGE}_{2}$ levels were decreased by about
6 -keto PGF levels were decreased by only $34 \%$.

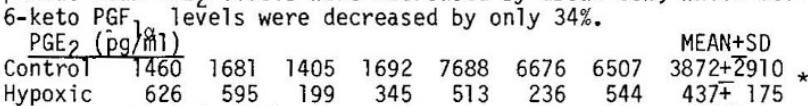

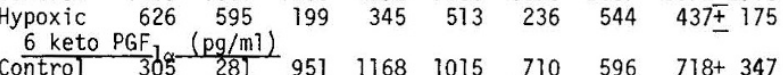
Hypoxic \begin{tabular}{llllllll}
378 & 269 & 175 & 378 & 201 & 1138 & 82 & $374 \pm$ \\
\hline
\end{tabular} ${ }^{*} \mathrm{p}<0.05$

Thus severe hypoxia in the rat pup decreases both $\mathrm{PGE}_{2}$ and 6keto PGF, however, the degree of suppression is different $(p<0.05)$. ${ }^{\alpha}$ In this model, therefore, under conditions of severe hypoxia 6-keto $\mathrm{PGF}_{1 \alpha}$ becomes the predominant circulating dilator prostaglandin.
1377 THROMBOXANE $B_{2}$ LEVELS IN NEONATES WITH PERSISTENT FETAL CIRCULATION. Cathy Hammerman, Elene Strates,
Stuart Berger and William Zaja. (Spon. by K.S. Lee), University of Chicago Medical Center, Department of Pediatrics, Chicago, IL.

Plasma levels of Thromboxane $B_{2}\left(T \times B_{2}\right)$ were determined by radioimmunoassay in seven infants with persistent fetal circulation (PFC) of various etiologies. The levels were found to be quite elevated as compared with those of seven neonates with other cardiorespiratory problems, but without PFC:

\begin{tabular}{lrrrrrrrr}
\hline PFC & 2426 & 12 & 2540 & 585 & 591 & 628 & 331 & $1016 \pm 1025$ \\
\hline Controls & 282 & 34 & 237 & 188 & 99 & 134 & 48 & $146 \pm 94$
\end{tabular}

A11 of the infants with PFC, except one, had $\mathrm{TxB}_{2}$ levels $>300 \mathrm{pg} /$ All of the infants with PFC, except one, had TXB2 levels $>300 p g$
$\mathrm{ml}$, while all of the controis had levels of $<300 \mathrm{pg} / \mathrm{ml}$. These differences are significant $(p<0.05)$.

of the PFC infants, two had $\beta$ strep sepsis, four had meconium aspiration pneumonia and two were prematures with HMD. Within the PFC group, however, the type of primary lung disease did not seem to make a difference in $\mathrm{TxB}_{2}$ levels. Two of the infants were thrombocytopenic; although, this in itself was not associated with higher $\mathrm{TxB}_{2}$ levels. Both infants with $\mathrm{TxB}_{2}$ levels with higher $\mathrm{TXB} 2$ levels. Both inf
$>2,000 \mathrm{pg} / \mathrm{ml}$ subsequentiy expired.

$\mathrm{TXB}_{2}$ is a potent vasoconstrictor which is noted to be elevated in some infants with PFC, with and without sepsis. This increased vasoconstrictor tone may play a role in the pathophysiology of $\mathrm{PFC}$, and may have prognostic implications.

ATRIAL TACHYCARDIA CAUSES HYDROPS IN FETAL LAMBS. 1378 Alfred Gest, Thomas Hansen, Craig Hartley, and Mark Giesler. Dept. of Pediatrics and Medicine, Baylor College of Medicine, Houston, Tx.

Although paroxysmal atrial tachycardia is a recognized cause of nonimmune hydrops fetalis, the mechanism by which it produces edema is unknown. We operated on 5 fetal lambs at 122-135 days gestation to study the relationship between atrial tachycardia and hydrops. We attached pacer wires to the left or right atria, inserted catheters into the inferior vena cava and aorta, and placed a reference catheter into the amniotic sac. After 3 days of recovery, we measured arterial blood gas tensions, hematocrit, plasma protein concentration, and aortic and venous pressures during a control period and while pacing at $300-320$ beats $/ \mathrm{m}$ Summary of results: ( $X \pm s_{x}$ : difference significant, $\left.p<0.05\right)$

$$
\begin{array}{ccccc}
\begin{array}{c}
\text { Arterial } \\
\mathrm{pH}
\end{array} & \mathrm{PO}_{2} \mathrm{PCO}_{2} & \begin{array}{c}
\text { Pressures } \\
\text { IVC Aorta }
\end{array} & \text { Hematocrit } & \begin{array}{c}
\text { Serum } \\
\text { [Protein] }
\end{array} \\
\text { (torr) } & \text { (torr) } & (\%) & (\mathrm{g} / \mathrm{dl})
\end{array}
$$
$\begin{array}{llllllll}\text { Control } 7.35 \pm 0.04 & 29 \pm 6 & 50 \pm 4 & 3 \pm 1 & 41 \pm 4 & 32 \pm 2 & 3.3 \pm 0.3 \\ \text { Pacing } 7.34 \pm 0.03 & 29 \pm 5 & 51 \pm 3 & 6 \pm 1 * & 38 \pm 2 & 32 \pm 5 & 2.9 \pm 0.3\end{array}$ Pacing $7.34 \pm 0.03$
During atrial pacing venous pressure doubled and plasma protein concentration decreased. A11 5 fetuses had peripheral edema, enlarged livers and ascites $(85 \pm 23 \mathrm{ml}$, protein concentration $2.1 \pm 0.6 \mathrm{~g} / \mathrm{dl}$ ). Since the ascitic fluid protein concentration was less than that of plasma and since arterial pH did not change we conclude that the edema was the result of increased venous pressure rather than an asphyxia-induced increase in capillary permeability to protein.

1379 AN ANALYSIS OF THE NEONATAL NURSE CLINICIAN

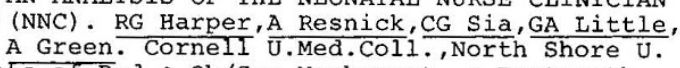

Hosp.,DepEs.of Ped.\& Ob/Gyn,Manhasset, \& DartmouthHitchcock Med.Ctr. Dept. Of Mat. \& Child Health, Hanover.
84 NNCs from 28 randomly selected NICUs were interviewed via telephone between Jan-Mar 82 . The interview included 7 open-ended, 21 fixed-alternative and 5 scaled-item questions. Sequence and wording were predetermined to delineate the group biographic profile professional education, lines of responsibility, skilis utilized and psychosocial aspects. $81(96 \%)$ were female, $80(95 \%)$ Caucasian, $38(45 \%)$ married and $9(11 \%)$ divorced. Educational preparation varied:18(228) held a master's degree, $35(41 \%)$ a bachelor's, 23(28\%) a diploma and 8 $(98)$ an associate's. $66(798)$ completed formal NNC programs; others completed inhouse NNC programs. 62(75\%) remained in their lst employment position since beginning their career; leaving time ranged from 6 mo-6 yr with 508 leaving after the 2nd employment year. Of 22 who left 15 remained in the NNC role. A trend was noted towards NNCs with associate's degrees performing more invasive tasks than those with master's degrees. Absence of a defined role was the primary factor felt to be responsible for nurse-physician conflict. The study documents the wide range of NNC education, demonstrates the group stability, points out the low crude turnover rate, and indicates the need for the NNC role to be more specifically defined. 